\title{
MELESTARIKAN DAN MENGEMBANGKAN WARISAN BUDAYA: KEBIJAKAN BUDAYA SEMARANGANDALAM PERSPEKTIF SEJARAH
}

\author{
Dhanang Respati Puguh \\ Departemen Sejarah Fakultas Ilmu Budaya \\ Universitas Diponegoro
}

Alamat korespondensi:dhanang_puguh@yahoo.com

Diterima/ Received: 18 Januari 2017 ; Disetujui/ Accepted: 24 Februari 2017

\begin{abstract}
Semarang has developed as a diverse city. The communities who lived in Semarang history has produced a hybrid culture patterned Semarang which in the next time become as "Semarangan culture". At that time of Indonesia's independence there is awareness to preserve the cultural heritage of Semarangan either by local governments and communities of Semarang. The preservation and development cultural heritage of Semarangan continues which among other things aims to establish a cultural identity for the community and theie city. However, such efforts have not been able to achieve the expected results, because the Semarangan culture is less able to perform in a stage of cultural life in their own city and national culture.
\end{abstract}

Keywords: Cultural heritage; Performing arts; Tradition ceremony; Cultural policy

\begin{abstract}
Abstrak
Semarang telah tumbuh sebagai kota yang majemuk. Komunitas-komunitas sejarah yang tinggal di Semarang telah menghasilkan kebudayaan Semarang yang bercorak hibrida yang pada masa kemudian dikenal sebagai "budaya Semarangan". Pada masa Indonesia merdeka terdapat kesadaran untuk melestarikan warisan budaya Semarangan baik oleh pemerintah daerah maupun masyarakat Semarang. Upaya-upaya untuk melestarikan dan mengembangkan warisan budaya Semarangan terus dilakukan yang antara lain bertujuan untuk membentuk identitas budaya bagi masyarakat dan kotanya. Namun, upaya-upaya itu belum mampu mencapai hasil yang diharapkan, karena budaya Semarangan kurang dapat tampil dalam panggung kehidupan budaya di kotanya sendiri dan budaya nasional.
\end{abstract}

Kata Kunci: Warisan budaya; Seni pertunjukan; Upacara tradisi; Kebijakan budaya

\section{PENDAHULUAN}

Seperti di sebagian besar negara yang sedang mengalami dekolonisasi, di Indonesia "negara bangsa dipandang sebagai pelindung kebudayaan dan pembendung imperialisme budaya” (Betts melalui Bogaerts, 2011: 256). Seiring dengan terbentuknya negara bangsa Indonesia, pada awal kemerdekaan muncul berbagai pemikiran dan gerakan untuk mencari format pembangunan kebudayaan Indonesia. Dari berbagai wacana yang dikemukakan oleh para ahli dalam bidang kebudayaan pada saat itu, dapat disimpulkan bahwa kebudayaan daerah merupakan sumber yang sangat kaya untuk membangun kebudayaan Indonesia (Puguh, 2015: 127). 
Pada awal kemerdekaan, pengelolaan warisan budaya merupakan salah satu isu penting yang diperbincangkan dalam wacana pembangunan kebudayaan Indonesia. Intinya, para pemimpin negara harus mengadakan politik kebudayaan yang merupakan perwujudan dari pembinaan negara dan masyarakat Indonesia baru atas dasar-dasar kebudayaan baru yang antara lain mencakup kesenian, kesusastraan, dan kesusilaan. Bangsa Indonesia tidak dapat hanya kembali ke zaman lampau. Namun demikian, warisan budaya merupakan latar belakang masyarakat Indonesia yang tidak dapat diabaikan. Oleh karena itu, pengelolaan warisan budaya merupakan salah satu langkah yang perlu dilakukan sebagai sebuah politik kebudayaan (Puguh, 2015: 138).

Sejak Kongres Kebudayaan Indonesia
1948, dekolonisasi menambah tingkat kebutuhan bagi pengambilan keputusan praktis untuk mewujudkan kebudayaan Indonesia. Sebagaimana klausul kebudayaan yang terdapat pada Undang-Undang Dasar Sementara 1950, pada awal 1950an pemerintah Indonesia akan melindungi kebebasan untuk mengusahakan kebudayaan, kesenian, dan ilmu pengetahuan (Jones, 2005: 95-96). Pemerintah melaksanakan pembangunan dalam bidang kebudayaan di bawah kewenangan dan koordinasi Kementerian Pendidikan, Pengajaran, dan Kebudayaan yang pada masa Orde Baru diubah menjadi Departemen Pendidikan dan Kebudayaan (Lindsay, 1995: 695).

Studi tentang politik kebudayaan dan kebijakan budaya di Indonesia telah dilakukan oleh beberapa ahli baik dari dalam maupun luar negeri, antara lain Jennifer Lindsay (1995), Joergen Hellman (1999), Tod Jones (2005), Julianti Parani (2011), dan Dhanang Respati Puguh (2015). Lindsay membahas tentang kebijakan budaya di Asia Tenggara; Hellman membahas tentang revitalisasi teater tradisional yang memfokuskan pada Longser; Jones membahas tentang kebijakan kebudayaan Indonesia selama periode 1950-2003; Parani membahas tentang seni pertunjukan Indonesia sebagai suatu politik kebudayaan; Puguh membahas tentang kebijakan-kebijakan budaya untuk melestarikan dan mengembangkan kebudayaan Jawa Surakarta. Di antara studi-studi yang telah dilakukan, belum ada satu pun yang menyinggung tentang kebijakan budaya Semarangan.

Sejalan dengan wacana pembangunan kebudayaan Indonesia pada awal kemerdekaan yang kemudian direalisasikan dalam kebijakankebijakan kebudayaan yang dilakukan oleh Pemerintah Pusat, tulisan ini akan membahas tentang upaya-upaya yang dilakukan oleh Pemerintah Daerah dan masyarakat Semarang dalam melestarikan dan mengembangkan warisan budayanya. Untuk memperoleh pembahasan yang utuh, dalam tulisan terlebih dahulu akan dibahas tentang jenis budaya Semarangan; dilanjutkan dengan pembahasan tentang upaya-upaya yang dilakukan untuk melestarikan dan mengembang-kannya; dan diakhiri dengan pembahasan tentang pencapaian dari upaya-upaya yang telah dilakukan, khususnya dalam kaitan dengan posisi budaya Semarangan dalam konstelasi budaya nasional.

\section{WARISAN BUDAYA SEMARANGAN: SENI TRADISI DAN UPACARA TRADISI}

\section{Seni Tradisi Semarangan \\ Seni Pertunjukan}

Ada empat jenis seni pertunjukan yang dapat dikategorikan sebagai seni tradisi Semarangan, yaitu Gambang Semarang, karawitan Semarangan, macapat Semarangan, dan tembang dolanan Semarang. Keterangan singkat tentang keempat jenis seni pertunjukan itu adalah sebagai berikut.

\section{a. Gambang Semarang}

Gambang Semarang berasal dari Gambang Kromong Jakarta. Gambang Kromong merupakan perpaduan antara unsur-unsur kesenian masyarakat Tionghoa dan bumiputera. Meskipun bukan kesenian asli Semarang, Gambang Semarang memiliki akar historis yang cukup kuat di kota Semarang. Sebelum kemunculannya, di kota ini telah ada kesenian yang mirip dengan Gambang Kromong, yaitu pat iem, yan kim, dan orkes gambang yang didukung oleh komunitas Tionghoa. Barangkali karena kemiripan itu, maka ketika Lie Hoe Soen dan 
kawan-kawan pada 1930-an ingin menciptakan kesenian yang khas Semarang, mereka mendatangkan seperangkat peralatan dan pelatih Gambang Kromong dan kemudian membentuk kelompok kesenian Gambang Semarang. Sejak saat itu pula Gambang Kromong di Semarang oleh masyarakat Semarang disebut Gambang Semarang. Gambang Semarang memiliki konsep estetis dan pola penyajian yang berbeda dari Gambang Kromong atau kesenian lain. Konsep estetis Gambang Semarang meliputi musik, nyanyian, tari, lawak, dan sastra (pantun). Penyajiannya diawali dari intrumentalia sebagai pembuka pertunjukan, dilanjutkan dengan lagu 'Gambang Semarang' sebagai tanda perkenalan, lagu vokal intrumentalia untuk mengiringi tarian, lawak, lagu vokal intrumentalia untuk mengiringi tarian, dan lagu penutup. Musik dan vokal merupakan unsur utama dalam pertunjukan Gambang Semarang, sehingga kedua unsur itu ada dalam hampir seluruh penampilannya. Instrumen musik dalam Gambang Semarang terdiri atas gambang, kromong (bonang), tiga buah rebab Cina (kongahyan, tehyan, dan sukong), suling, gong, kempul, kendhang, ketipung, kecrek, dan ningnong (Utama dan Puguh, 2013: 372-373).

\section{b. Karawitan Semarangan}

Di Semarang sebenarnya terdapat karawitan gaya Semarang yang dikenal dengan sebutan karawitan gagrag Semarangan. Seni musik tradisi ini menggunakan instrumen gamelan yang tidak berbeda dari karawitan gaya Surakarta. Struktur gendhing-gendhing Semarangan juga sama dengan gendhing-gendhing gaya Surakarta. Perbedaannya terletak pada pola permainan instrumen kendhang, bonang, dan peking. Karawitan gagrag Semarangan memiliki repertoar khusus yang disebut gendhing-gendhing Semarangan. Berdasar pada dokumentasi rekaman RRI Semarang dan Lokananta Surakarta setidaknya ada sekitar 15 repertoar gendhing Semarangan; yang terdiri atas gendhing bonang Semarangan (intrumentalia) dan gendhing Semarangan dengan menggunakan vokal (Utama dan Puguh, 2013: 374-375).

\section{c. Macapat Semarangan}

Macapat Semarangan adalah salah satu jenis seni resitasi yang tumbuh dan berkembang di Semarang. Tidak diketahui titi mangsa kemunculan dan penciptanya. Oleh karena sistem pewarisannya yang menggunakan tradisi lisan, mengakibatkan khazanah seni ini tidak banyak diketahui dan hampir punah, dan sastra pesisiran yang digunakan sebagai lirik dalam macapat Semarangan juga tidak dapat diketahui. Walaupun demikian, keberadaannya telah diakui oleh kalangan seniman karawitan. Hal ini paling tidak dapat dibuktikan dengan pencantuman dhandhanggula Semarangan dalam buku berjudul Macapat yang ditulis oleh Gunawan Sri Hastjarjo yang berisi tentang berbagai titilaras macapat. Berdasar inventarisasi yang dilakukan oleh W. Sinung Hardjo, setidaknya ada 17 cengkok macapat Semarangan yaitu asmarandana tiga cengkok, sinom tiga cengkok, pangkur tiga cengkok, durma dua cengkok, mijil satu cengkok, kinanthi satu cengkok, dan dhandhanggula empat cengkok dengan menggunakan laras slendro dan pelog (Utama dan Puguh, 2013: 377-379).

\section{d. Tembang Dolanan}

Overbeck dalam bukunya berjudul Javaansche Meisjessplen en Kinderliedjes menyebutkan adanya beberapa tembang dolanan beserta liriknya yang menyinggung tentang Semarang yaitu Jongjang Semarang I, Jongjang Semarang II, Jumplo Kenthang II, Cumplo Kenalo, Cikarcikar Goyang, Jongkang Kung, Ceplok Endhog, Enting-enting Selawe, dan Suri-Suri Dablang. Lirik-lirik tembang dolanan itu tampaknya merefleksikan pengakuan terhadap kehadiran kebudayaan lain dalam ruang kesadaran kolektif masyarakat termasuk anak-anak. Sayang sekali, melodi tembang-tembang dolanan yang berkaitan dengan Semarang ini tidak diketahui dan khazanah tembang dolanan ini dapat dikatakan mengalami kepunahan (Utama dan Puguh, 2013: 380-382).

\section{Seni Rupa: Batik Semarang}

Salah satu khasanah seni rupa tradisi di kota Semarang yang perlu mendapatkan perhatian adalah batik Semarang. Menurut Dewi Yuliati 
(2009), batik Semarang adalah batik yang diproduksi oleh orang atau warga kota Semarang, di kota Semarang terutama dengan motif atau icon-icon khas kota Semarang sebagai kota pesisir. Ciri-ciri motif batik Semarang tidak berbeda jauh dengan motif batik di kota-kota pesisir utara Pulau Jawa. Ciri-ciri yang dapat diidentifikasi adalah: bebas tidak terikat pada aturan-aturan tertentu, ragam hias flora dan fauna, ragam hias besar dan tidak terinci, serta warna cerah mencolok. Namun demikian, ada yang membedakan antara motif batik Semarang dengan batik pesisir lainnya.

Selain batik Semarang, di Semarang juga terdapat busana yang dianggap sebagai busana Semarangan, yaitu busana pengantin haji, busana encik, busana denok dan kenang.

\section{Upacara Tradisi Semarangan}

Ada tiga upacara tradisi yang dapat dianggap sebagai upacara tradisi Semarangan, yaitu upacara dhugdheran, upacara pengantin sunat, dan upacara pengantin daya Semarangan.

\section{a. Upacara Dhugdheran}

Penyelenggaraan dhugdheran bermula dari adanya perbedaan pendapat dalam menentukan permulaan bulan puasa (Ramadhan). Perbedaan itu mendorong Kangjeng Bupati R.M.T.A. Purbaningrat untuk menentukan awal puasa, yaitu dengan membunyikan bedhug masjid agung dan meriam di halaman kabupaten sebanyak tiga kali. Bunyi 'dhug' dari bedhug dan 'dher' dari meriam kemudian digunakan untuk menyebut upacara ini sebagai dhugdheran. Upacara dhugdheran yang kali pertama muncul pada 1881 ini, dalam perkembangan semakin menarik perhatian masyarakat Semarang dan sekitarnya. Hal ini menarik minat sejumlah pedagang dari berbagai daerah yang menjual makanan, minuman, dan mainan anak-anak yang terbuat dari tanah liat (gerabah), mainan dari bambu (seruling, gasing), dan mainan dari kertas berbentuk hewan berkaki empat dengan kepala mirip naga yang kemudian dikenal dengan nama warak ngendhog. Pada perkembangan selanjutnya sampai dengan sekarang, warak ngendhog dijadikan icon upacara tradisi dhugdheran (Rochwulaningsih, dkk., 2010; Selayang Pandang Kota Semarang, 2008: 86) .

\section{b. Upacara Pengantin Sunat}

Upacara pengantin sunat menandai masa peralihan anak laki-laki ke dalam usia akil balig. Anak yang akan disunat/ dikhitan didandani dengan busana a la Timur Tengah, yaitu mengenakan baju gamis, tutup kepala alfiyah, dan sorban putih serta diarak keliling kampung dengan naik kuda yang berjalan perlahan. Arakarakan pengantin sunat selalu meriah, karena diikuti oleh para pengiring yang terdiri atas rombongan pengendara sepeda motor yang berjalan pelan-pelan untuk 'membuka' jalan. Di belakangnya adalah kelompok pemain musik rebana, kadang-kadang juga kelompok drum band, kelompok pembawa hiasan dari kertas beraneka warna yang diberi tangkai tongkat sepanjang sekitar dua meter, dan kelompok pencak silat yang memainkan atraksi memutar tongkat yang di kedua ujungnya dililit kain yang dinyalakan (Puguh dkk., 2009: 106-107).

\section{c. Upacara Pengantin Gaya Semarangan}

Tata upacara pengantin gaya Semarangan memiliki tahapan yang sederhana, yaitu proses pencarian dan pengenalan calon pengantin, lamaran, dan upacara pernikahan. Upacara pernikahan terdiri atas tiga tahap yaitu lek-lekan dan ukupan, ijab kabul, dan ngarak pengantin. Setidaknya ada tiga versi urutan peserta ngarak pengantin di Semarang, yaitu versi Kampung Kauman, Kampung Begog, dan keluarga Tasripin. Dalam acara ramah tamah disajikan menu-menu makanan khas Semarang yaitu Ganjel Rel, Jabika, Lumpia, Ketan Biru, Cucur, Tahu Pong, Wedang Rondhe, dan lain-lain. Dalam acara itu juga disuguhkan kesenian seperti Rodat, Gambang Semarang, dan atau Tari Ular ( Tata Cara Upacara Pengantin Gaya Semarangan, 2009; Rochwulaningsih, dkk., 2010).

\section{Upaya-upaya Pelestarian dan Pengembangan Budaya Semarangan}

Pada awal kemerdekaan (1949) sampai akhir dasawarsa 1970an telah muncul upaya-upaya 
untuk melestarikan dan mengembangkan Gambang Semarang dari masyarakat Semarang (baik secara individu maupun berkelompok) dan Pemerintah Kotamadya Semarang. Pada masa itu dapat dikatakan, bahwa orang-orang Tionghoa Semarang menjadi motor penggerak dalam upaya pelestarian dan pengembangan Gambang Semarang. Beberapa orang Tionghoa yang berkontribusi dalam pelestarian Gambang Semarang adalah The Lian Kian, Yauw Tia Boen, dan Goh Kim Djoen dengan para pemain yang terdiri atas orang-orang Tionghoa dan Jawa (Puguh, dkk., 1998/1999: 32-35).

Upaya-upaya untuk melestarikan Gambang Semarang terus berlanjut pada dasawarsa berikutnya. Grup Aktivitas Seniman Remaja (ASR) di Semarang di bawah pimpinan Burhanuddin membentuk "Gambang Remaja" pada 1985. Pelatihnya adalah Jayadi dan Juri, keduanya adalah seniman Gambang Semarang. "Gambang Remaja" sering dipentaskan untuk menyambut wisatawan mancanegara di pelabuhan Semarang. Selain itu, ASR juga pernah mementaskan opera Andhe-andhe Lumut dengan iringan musik Gambang Semarang di Gedung Olah Raga Simpang Lima Semarang. Penonton pertunjukan ini harus membayar dengan membeli tiket, dan jumlah penontonnya cukup banyak. Penataan tari dan busana "Gambang Remaja" ditangani oleh Asri Meiati, pemimpin Sanggar Asri Budaya. Penataan tersebut dibuat atas persetujuan Iman Prakosa, Kepala Bidang Kebudayaan Kotamadya Semarang pada saat itu. Pada 1986 sejarawan dan budayawan Semarang Amen Budiman mendirikan perkumpulan Gambang Semarang "Kembang Goyang". Perkumpulan ini sering tampil di berbagai acara antara lain pameran masakan Semarang, pesta perkawinan, pesta ulang tahun, penyambutan tahun baru Masehi (Puguh, dkk., 1998/1999: 35-36).

Pada dasawarsa 1980an, selain muncul perhatian terhadap Gambang Semarang juga terdapat upaya-upaya untuk melestarikan dan mengembangkan karawitan dan macapat Semarangan. Pada waktu itu, upaya-upaya untuk melestarikan macapat Semarangan dilakukan oleh Pemerintah Kotamadya Semarang dengan menginventarisasi berbagai jenis macapat
Semarangan. Selain itu, perhatian pada macapat dan karawitan Semarangan juga diberikan oleh seniman terkenal Ki Nartosabdho. Ia melakukan penggalian, pelestarian, dan pengembangan macapat Semarangan melalui karya-karya macapat dan gendhing-nya. Dalam dunia macapat Semarangan, Ki Nartosabdho menambah variasi cengkok macapat Semarangan. Ia juga menggubah dan menyusun gendhing-gendhing yang digarap berdasar tradisi karawitan Semarangan. Pengembangan yang dilakukan oleh $\mathrm{Ki}$ Nartosabdho dilakukan dengan menambahkan vokal pada karya-karya gendhing Semarangan-nya. Pada masa kejayaan Ki Nartosabdho, karawitan dan macapat Semarangan memiliki kesempatan yang luas untuk dikenal publik, karena disajikan dalam pergelaran wayang kulitnya dan melalui pita rekaman kaset komersial. Selain itu, macapat dan gendhing-gendhing Semarangan juga sering diperdengarkan kepada publik melalui siaransiaran karawitan Radio Republik Indonesia (RRI) Semarang setidaknya sampai dengan dasawarsa 1980an. Pada dasawarsa 1990an siaran gendhing-gendhing Semarangan mengalami penurunan frekuensi yang disebabkan oleh tokoh-tokoh karawitan RRI Semarang yang menguasai garap gendhinggendhing Semarangan pensiun dan meninggal dunia. Gendhing-gendhing Semarangan sama sekali tidak lagi dapat kita dengarkan ketika RRI Semarang membekukan korps musik yang dimilikinya dan menjadikan tenaga-tenaga senimannya sebagai tenaga-tenaga administrasi pada 2000 seiring dengan posisinya sebagai lembaga penyiaran publik (LPP).

Dalam bidang seni rupa, sampai dengan dasawarsa 1970an masih ada beberapa perusahaan yang meneruskan usaha batik di Kampung Batik. Pada 1980 usaha batik tidak hanya terbatas di Kampung Batik, tetapi juga di tempat lain yang ditandai oleh kemunculan perusahaan batik "Sri Retno" di Jatingaleh. Perusahaan ini memproduksi batik dengan motif yang bervariasi termasuk motif icon Kota Semarang, seperti Tugu Muda (Yuliati, 2009).

Pada dasawarsa 1990an muncul perhatian yang cukup luas dari masyarakat Semarang untuk melestarikan dan mengembangkan 
Gambang Semarang. Atas dorongan dari Iman Prakosa, Agus Supriyanto, staf Seksi Kebudayaan Kota Semarang menyusun tari Gado-gado Semarang dengan iringan musik Gambang Semarang dan menggunakan lagu Gado-gado Semarang karya Kelli Puspito yang dibuat atas permintaan Hadiyanto, walikota Semarang pada periode 1970an. Departemen Pendidikan dan Kebudayaan Kotamadya Semarang kemudian memasyarakatkan tari Gado-gado Semarang melalui jalur pendidikan formal. Guru-guru tari di kota Semarang mendapatkan penataran dengan materi tarian tersebut. Selanjutnya tarian itu diajarkan di beberapa SMP dan SMU di Kotamadya Semarang. Pada awal 1990an Institut Keguruan dan Ilmu Pendidikan (IKIP) Negeri Semarang (sekarang Universitas Negeri Semarang, UNNES) juga muncul dalam wacana pengembangan Gambang Semarang. Bintang Hanggoro Putra, S.Sn. dosen pada institusi tersebut menciptakan tari Denok dengan iringan musik dan lagu Gambang Semarang. Tarian itu juga diajarkan di kalangan mahasiswa Jurusan Seni Drama Tari Musik IKIP Semarang dan sanggar tari yang dibinanya (Puguh dkk., 1998/1999: 36-37). Untuk menggairahkan kehidupan Gambang Semarang pada dasawarsa 1990an juga diadakan lomba tari Semarangan antarsiswa-siswi SMP dan SMU di kota Semarang. Keikutsertaan generasi muda pada kegiatan yang dilakukan oleh Departemen Pendidikan dan Kebudayaan Kotamadya Semarang dan IKIP Semarang masih terbatas pada bidang tari.

Pada 1993 muncul perhatian dari Fakultas

Sastra Universitas Diponegoro (UNDIP) terhadap Gambang Semarang. Berawal dari penyelenggaraan pameran budaya Semarangan dalam rangka Dies Natalis UNDIP yang menampilkan peralatan musik Gambang Semarang dan masakan khas Semarang, kegiatan ini terus berlanjut dengan penyelenggaraan sarasehan bertajuk "Pelestarian dan Pengembangan Gambang Semarang” pada 20 Januari 1994 yang ditindaklanjuti dengan Lokakarya Pengembangan Gambang Semarang pada 25 Juli 1994 (Puguh dkk., 1998/1999: 38). Dari kedua kegiatan itu memunculkan gagasan untuk mengadakan pelatihan guna melestarikan dan mengembangkan Gambang Semarang.

Pelatihan Gambang Semarang di Fakultas Sastra UNDIP diikuti oleh mahasiswa, dosen, dan karyawan yang memiliki minat terhadap kesenian. Pelatihan menggunakan peralatan yang dibeli dari Jayadi. Jayadi dan Juri menjadi pelatih musik Gambang Semarang. Pada saat itu pelatihan dilakukan terhadap semua unsur seni yang membentuk seni pertunjukan Gambang Semarang yang meliputi musik, vokal, tari, dan lawak. Penyelenggaraan pelatihan di bawah pimpinan Dra. Dewi Yuliati, M.A. itu juga telah berhasil menyusun komposisi tari berjudul Gambang Semarang. Hasil pelatihan ini untuk kali pertama disajikan dalam Lokakarya Kesenian Gambang Semarang dalam rangka kegiatan pengabdian kepada masyarakat pada 14 November 1995 di Hotel Graha Santika Semarang (Puguh, 1995). Gambang Semarang Fakultas Sastra UNDIP telah berkesempatan untuk mengisi berbagai acara di kota Semarang.

Pada 1998-2000 Tim Peneliti Fakultas Sastra UNDIP memenangkan Program Penelitian Hibah Bersaing dari Direktorat Jenderal Pendidikan Tinggi Departemen Pendidikan dan Kebudayaan. Selain menyusun naskah akademis yang berisi tentang sejarah, fungsi, unsur-unsur seni Gambang Semarang dan budaya Semarang yang dapat mendukung pengembangannya, Tim Peneliti juga menyusun komposisi pertunjukan Gambang Semarang sebagai identitas budaya Semarang, yang mencakup seni musik, vokal, tari, dan lawak. Pelatihan dilakukan dengan melibatkan mahasiswa, dosen, dan karyawan UNDIP dalam rentang waktu hampir satu tahun. Hasil penataan dipentaskan pertama kali dalam Lokakarya Penataan Kesenian Gambang Semarang sebagai Identitas Budaya di Hotel Patra Jasa pada 8 Desember 1999 (Puguh, dkk., 1999/2000). Hasil penataan ini juga sering dipentaskan dalam berbagai acara yang diselenggarakan oleh UNDIP.

Pada dasawarsa pertama sampai pertengahan dasawarsa kedua 2000an terdapat upaya-upaya yang semakin giat yang dilakukan oleh pemerintah dan masyarakat kota Semarang dalam melestarikan dan mengembangkan 
budaya Semarangan. Hal ini antara lain ditunjukkan dengan adanya berbagai kegiatan untuk mempertahankan eksistensi dan mengekspos budaya Semarangan kepada masyarakat secara lebih luas.

Pada 2003 Tim Peneliti Fakultas Sastra UNDIP mengadakan kegiatan sosialisasi dan pelatihan Gambang Semarang kepada Mahasiswa Unit Kegiatan Mahasiswa Kesenian Jawa Universitas Diponegoro (UKMKJ UNDIP). Mereka dilatih untuk memainkan seluruh intrumen musik dan menyajikan repertoar-repertoar lagu Gambang Semarang, menyanyikan repertoar-repertoar lagu Gambang Semarang, menarikan komposisi tari Gambang Semarang dan Goyang Semarang, serta menyajikan lawak Gambang Semarang. Dari pelatihan itu telah berhasil dibentuk kelompok seni Gambang Semarang yang semua peraganya terdiri atas mahasiswa yang tergabung dalam UKMKJ UNDIP (Puguh, dkk., 2003). Kelompok ini juga sering mendapatkan kesempatan untuk mengisi berbagai kegiatan baik dari kalangan pemerintah, perguruan tinggi, alumni UNDIP, dan swasta; salah satu di antaranya adalah pertunjukan dalam acara Pasar Semawis. Suatu hal yang menarik untuk mendapatkan perhatian adalah ternyata ada kegairahan yang besar dari mahasiswa UKMKJ UNDIP untuk berlatih Gambang Semarang. Para pemain dengan inisiatif sendiri dan kemampuan yang dimilikinya mencoba untuk "menularkan" pengetahuan dan ketrampilan bermain seni Gambang Semarang pada anggotaanggota dari angkatan yang lebih muda. Dengan demikian, terjadi regenerasi pemain-pemain Gambang Semarang di tubuh UKMKJ UNDIP tanpa banyak campur tangan dari para pembinanya yang telah disibukkan dengan kegiatan Tridharma Perguruan Tinggi.

Kemudian, suatu hal yang sangat membanggakan adalah setelah melakukan pelatihan dan persiapan yang panjang UKM KJ UNDIP yang didukung oleh dosen-dosen Fakultas Ilmu Budaya UNDIP berhasil menggelar acara bertajuk "Titiwanci Gambang Semarang” di Balai Prajurit, bekas rumah kediaman Oei Tiong Ham di Gergaji pada 2009. Pergelaran ini mendapatkan perhatian yang cukup luas dari masyarakat Semarang dan menjadi pementasan Gambang Semarang yang monumental dari UKMKJ UNDIP. UKMKJ UNDIP bekerja sama dengan Radio Republik Indonesia Semarang juga merekam lagu-lagu dan musik iringan tari hasil penataan Fakultas Sastra UNDIP.

Lulus dari UNDIP ternyata tidak menghentikan alumni-alumni UKMKJ UNDIP untuk berkiprah dalam jagad seni Gambang Semarang. Mereka kemudian berinisiatif untuk membentuk organisasi sebagai wadah untuk berekspresi seni dengan nama Gambang Semarang Art Company (GSAC) yang diketuai oleh Tri Subekso, S.S. mantan Ketua UKMKJ UNDIP. Pembentukan organisasi ini dilatarbelakangi oleh adanya keinginan untuk turut serta dalam pelestarian Gambang Semarang. Dengan lembaga itu mereka dapat menyalurkan dan mewujudkan ide kreatifnya untuk melestarikan Gambang Semarang.

GSAC secara resmi dibentuk pada 21 November 2012. Pemilihan nama tersebut tidak lepas dari visi dan misi yang ingin dicapai yaitu pelestarian Gambang Semarang. Adapun visinya adalah "Gambang Semarang sebagai bentuk kesenian pertunjukan akulturatif yang menonjolkan kreativitas berkarya dalam kandungan nilai estetika dan tradisional." Visi itu dijabarkan ke dalam tiga misi, yaitu: 1). melakukan upaya pelestarian, pengembangan, dan penciptaan karya seni melalui aspek tari, musik, vokal, lawak serta artistik pertunjukan yang didasarkan pada penggalian kembali akar historis kesenian Gambang Semarang; 2) memperkuat eksistensi kesenian Gambang Semarang sebagai icon Semarang yang mengandung nilai-nilai estetika dan tradisional dalam semangat keberagaman dan kemajuan; dan 3) melakukan terobosan pengenalan kesenian Gambang Semarang ke dalam berbagai media baik secara visual maupun audiovisual.

Seiring dengan perkembangannya, GSAC tidak sekadar untuk mewadahi ide kreatif dari anggotanya saja, tetapi juga mewadahi masyarakat pecinta Gambang Semarang baik dari kalangan media, seniman, umum, profesional, komunitas seni maupun budayawan. Pada pertengahan 2013, GSAC memantapkan 
diri dengan mengusung tagline "New Spirit of The Hybrid Folklore". Penentuan tagline ini tidak terlepas dari faktor sejarah, pesan, dan semangat akulturasi budaya yang membentuk Gambang Semarang pada awalnya.

Dalam usianya yang belum genap satu tahun, GSAC telah berhasil menggelar belasan acara. Kiprah GSAC mendapat perhatian dari media cetak dan elektronik. Setidaknya telah ada 15 tulisan di berbagai media cetak dan enam di media elektronik televisi yang memberitakan kegiatan-kegiatan GSAC. Sampai dengan usianya yang ketiga GSAC masih menggelar pertunjukan Gambang Semarang. Aktivitasaktivitas GSAC telah memberikan makna tersendiri dalam pelestarian, pengembangan, dan pemasyarakatan Gambang Semarang kepada khalayak luas khususnya generasi muda.

Semangat GSAC tampaknya menjadi inspirasi bagi sebagian mahasiswa Fakultas Ilmu Budaya UNDIP untuk membentuk Kelompok Gambang Semarang (KGS FIB UNDIP). Mereka giat berlatih musik dan tari Gambang Semarang dan telah berpentas dengan tajuk "Srawung Kampung: Nggambang Neng Rowosari” pada 12 Oktober 2013 dan mengisi acara seminar yang diselenggarakan oleh FIB UNDIP (Puguh, 2013).

Setiap tahun Pemerintah Kota Semarang menggelar Festival Warak (2001-2006) untuk mengawali upacara tradisi Dhugdheran. Setiap kecamatan diwajibkan untuk mengirimkan satu kontingen seni untuk tampil dalam Festival Warak tersebut. Dalam festival ini berbagai koreografi yang memanfaatkan warak ditampilkan. Selain itu, Pemerintah Kota Semarang juga menggelar Festival Musik Gambang Semarang (2004), Festival Tari Semarangan (2011-2012) dalam berbagai format, dan selama dua tahun berturut-turut menyelenggarakan Sarasehan Seni Kota Semarang untuk menyosialisasikan dan mendekatkan Gambang Semarang kepada generasi muda.

Dalam bidang seni batik juga terdapat kegairahan dari masyarakat Semarang untuk mengembangkan batik Semarang. Pada 2000 tumbuh dan berkembang perusahaan batik "Umizie" di Tembalang yang pada pertengahan
2006 berganti nama menjadi "Sanggar batik Semarang 16". Perusahaan ini memproduksi batik dengan motif-motif Semarang dari abad XX dan motif icon Kota Semarang. Pada 2006 muncul dua usaha kerajinan, yaitu "Batik Kinanti” yang dikelola oleh Siti Kholifah dan usaha batik di Jalan Borobudur yang dikelola oleh Suci Yulianti. Setahun kemudian pada 2007 didirikan usaha batik "Semarang Indah" di Kampung Batik yang merupakan salah satu hasil kegiatan Pelatihan Membatik yang diselenggarakan oleh Dewan Kerajinan Daerah Kota Semarang pada Juni-Juli 2006. Motif-motif yang dihasilkan terutama motif-motif Semarang baik yang tradisional maupun yang kontemporer (Yuliati, 2009).

Dalam aspek upacara tradisi setiap tahun Pemerintah Kota Semarang juga menggelar tradisi Dhugdheran yang dalam perkembangannya juga mendapatkan sentuhan untuk dijadikan sebagai salah satu atraksi wisata di Kota Semarang. Pemerintah Kota Semarang juga menggelar acara Sarasehan dan Ekspos Pengantin Semarangan Tradisional pada 2009. Dari kegiatan itu kemudian terbit buku Tata Cara Upacara Pengantin Gaya Semarangan (2009).

Upaya-upaya yang dilakukan oleh pemerintah dan masyarakat kota Semarang itu juga mendapatkan dukungan dari beberapa lembaga penyiaran seperti RRI Stasiun Semarang, TVKu, Cakra Semarang TV, dan SCTV melalui program-program siaran seni dan budaya tradisi yang antara lain mengangkat eksistensi Gambang Semarang, batik Semarang, dan upacara tradisi Semarang. Pada acara-acara siaran itu penulis pernah bertindak sebagai narasumber. Bahkan, didasari oleh keprihatinan terhadap eksistensi Gambang Semarang, mahasiswa Jurusan Komunikasi UNDIP juga menyusun film dokumenter tentang Gambang Semarang untuk tugas akhirnya yang juga ditayangkan pada acara Sluman-Slumun Semarangan Cakra Semarang TV (2013).

Keseriusan Pemerintah Kota Semarang untuk melestarikan, mengembangkan, dan memanfaatkan seni dan upacara tradisi di Kota Semarang ditunjukkan dengan penyusunan Naskah Akademik tentang Pelestarian, 
Pengembangan, dan Pemanfaatan Seni dan Upacara Tradisi di Kota Semarang yang dijadikan landasan untuk menyusun Rancangan Peraturan Daerah (Raperda). Namun, sampai saat ini penulis tidak mengetahui tentang perjalanan Raperda tersebut; apakah telah berhasil disahkan menjadi Peraturan Daerah yang pada gilirannya dapat digunakan sebagai payung hukum dalam upaya-upaya pelestarian, pengembangan, dan pemanfaatan seni dan upacara tradisi di Semarang atau belum.

Walaupun Pemerintah Kota Semarang telah melakukan berbagai upaya untuk melestarikan dan mengembangkan budaya Semarangan, berbagai kalangan (para praktisi dan pegiat seni) menganggap bahwa upayaupaya itu tampak kurang sistematis dan kurang memiliki visi yang jelas terhadap arah pengembangan budaya Semarangan. Hal ini diduga merupakan akibat dari pergantian pimpinan Pemerintah Daerah Semarang khususnya para birokrat kebudayaannya yang memiliki "selera" yang berbeda dan keterbatasan anggaran untuk menopang kegiatan bidang kebudayaan. Dengan demikian, programprogram lebih berkesan sporadis dan kurang menunjukkan adanya kontinuitasnya.

\section{PENCAPAIAN: BUDAYA SEMARANGAN DALAM KONSTELASI BUDAYA NASIONAL}

Sebagai warga Semarang yang selama hidup tinggal di Semarang, memiliki minat terhadap studi sejarah kebudayaan Indonesia, dan terlibat dalam aktivitas-aktivitas pelestarian dan pengembangan budaya Semarangan, penulis merasakan dan mendapat kesan bahwa keberadaan budaya Semarangan kurang mendapatkan tempat di kalangan warga masyarakatnya sendiri. Budaya Semarangan yang berupa seni dan upacara tradisi tampak kurang dapat tampil dalam panggung kehidupan budaya di kotanya sendiri. Seni pertunjukan tradisinya kurang mendapatkan tempat di hati masyarakat, bahkan termarginalisasi oleh keberadaan seni pertunjukan tradisi lain dan seni budaya moderen yang berkembang di Semarang.
Gambang Semarang dapat dikatakan hanya hidup di perkumpulan seni dan pada masa kemudian di kampus. Kehidupan Gambang Semarang mengalami pasang surut, tetapi lebih banyak surut daripada pasangnya. Saat ini secara kuantitatif setidaknya ada tiga institusi yang masih mengadakan pelatihan Gambang Semarang, yaitu GSAC, KGS, dan sanggar seni yang dikelola oleh keluarga Bintang Hanggoro Putro. GSAC dan KGS menyelenggarakan latihan secara insidental di kalangan anggotanya. Dari segi kualitas baik kemampuan para pemainnya maupun penggarapannya belum terjadi perubahan yang signifikan mengingat kegiatan ini merupakan ekstrakurikuler bagi mahasiswa dan merupakan kegiatan sampingan dari para anggota GSAC. Dari segi vokabuler belum ada perubahan atau penambahan vokabuler lagu dan peningkatan kualitas penggarapannya. Ketiga kelompok itu kadangkadang tampil di berbagai acara yang diselenggarakan oleh berbagai pihak dan festival yang diselenggarakan oleh Dinas Kebudayaan dan Pariwisata Kota Semarang. Saat ini sangat jarang dijumpai acara-acara di kampungkampung perkotaan yang menjadikan Gambang Semarang sebagai salah satu hiburan, walaupun GSAC dalam bebarapa tahun terakhir ini telah melakukan terobosan untuk pentas di kampungkampung untuk mendekatkan Gambang Semarang kepada masyarakat Semarang dan dikenal oleh masyarakat luas.

Pada akhir dasawarsa 1970an dan dasawarsa 1980an karawitan dan macapat Semarangan pernah populer melalui RRI Semarang dan Paguyuban Karawitan Condhong Raos di bawah pimpinan KI Nartosabdho. Saat ini karawitan dan macapat Semarangan mungkin sudah tidak dikenal oleh masyarakat Semarang dan sangat jarang muncul dalam panggungpanggung seni karawitan. Gendhing-gendhing Semarangan paling hanya sesekali tampil dalam klenengan di pesta perkawinan yang menggunakan seni karawitan Jawa sebagai salah satu hiburannya yang sekarang pun juga semakin jarang yang menggunakannya.

Batik Semarang yang masih terus dikembangkan, sampai saat ini masih kalah pamor dan populer dibandingkan dengan batik- 
batik yang dikembangkan oleh kota-kota lain di Jawa Tengah, seperti batik Surakarta, Yogyakarta, termasuk batik-batik pesisiran lainnya seperti batik Lasem dan batik Pekalongan. Sepengetahuan penulis, dibandingkan dengan tradisi batik-batik yang telah disebutkan, produk batik Semarang juga masih jarang digunakan oleh warganya sendiri.

Demikian juga dengan upacara tradisi yang berupa upacara pengantin Semarang dan upacara pengantin sunat. Sejak kecil sampai dengan saat ini penulis sangat jarang menjumpai praktik-praktik upacara pengantin tradisi Semarangan. Dari waktu ke waktu upacara pengantin Semarangan semakin jarang digunakan oleh masyarakat Semarang sebagai pemilik dari kebudayaan itu. Dengan demikian, busana Semarangan-nya pun jarang digunakan oleh masyarakat Semarang. Mungkin satusatunya upacara tradisi yang eksis dan mendapat tempat di hati warga masyarakat Semarang sampai saat ini adalah upacara tradisi dhugderan dengan warak sebagai penandanya. Walaupun masih terdapat kontroversi tentang bentuknya, warak tampaknya relatif telah menjadi salah satu identitas budaya Semarang daripada unsur budaya Semarangan lainnya, walaupun belum mampu tampil sebagai identitas budaya yang 'menasional'.

Budaya Semarangan kurang berkembang dan diapresiasi oleh masyarakat Semarang saat ini. Hal ini diduga karena masyarakat yang tinggal di kota Semarang secara kultural bukanlah pendukung budaya Semarangan, karena mereka bukanlah warga "asli" Semarang. Mereka kebanyakan adalah warga pendatang yang menjadi pendukung dari kebudayaan asal mereka masing-masing. Warga "asli' Semarang yang masih bertempat tinggal di Semarang diduga juga telah "meninggalkan" budayanya sendiri; berorientasi ke budaya lain. Selain itu, dalam kasus Gambang Semarang - kesenian ini dianggap sebagai budaya yang "diimpor" dari masyarakat Betawi yang dikembangkan oleh masyarakat Tionghoa di Semarang. Sementara itu, kehidupan seni karawitan dan macapat Semarangan sebenarnya berada di bawah bayang-bayang dominasi seni karawitan gaya Surakarta. Karawitan dan macapat Semarangan didukung dan dikembangkan oleh para pengrawit RRI Semarang dan Paguyuban Karawitan Condhong Raos pimpinan Ki Nartosabdho yang notabene bukanlah warga “asli” Semarang. Para pengrawit RRI Semarang dan Condhong Raos mayoritas berasal dari beberapa daerah yang secara kultural menjadi bagian dari wilayah kebudayaan Jawa Surakarta dan Yogyakarta. Pada masa yang lebih kemudian sebagian para pengrawit RRI Semarang adalah alumni-alumi Sekolah Menengah Karawitan Indonesia (SMKI) Surakarta yang kurikulumnya juga tidak mengajarkan karawitan tradisi Semarangan. Mereka lebih banyak bergaul dengan karawitan tradisi Surakarta atau Yogyakarta. Selain itu, saat ini Semarang tidak memiliki seniman karawitan yang andal, kreatif, dan produktif dalam menghasilkan atau mengembangkan

gendhing-gendhing Semarangan.

Dalam konstelasi yang lebih luas, tampaknya budaya Semarangan juga belum mampu tampil dalam panggung budaya nasional. Sebagai salah satu varian dari kebudayaan Jawa, budaya Semarangan tampak kalah pamor untuk tampil dalam panggung budaya nasional dibandingkan dengan budaya Jawa Surakarta atau budaya Jawa Yogyakarta yang merupakan dua varian budaya Jawa yang dominan. Tanpa mengurangi rasa hormat kepada para seniman dan budayawan yang telah memperjuangkan kemajuan budaya Semarang, penulis berpendapat bahwa budaya Semarangan belum mampu tampil dalam panggung budaya nasional. Memang telah banyak upaya untuk mengembangkan tari Semarangan dan tampil dalam acara-acara pesta seni yang diselenggarakan di Jakarta atau luar negeri, namun hal itu belum mampu mengatrol posisi budaya Semarangan dalam panggung budaya nasional.

Dalam bidang budaya khususnya seni tradisi tampaknya Semarang belum memiliki suatu yang diperhitungkan dalam budaya nasional. Hal ini terjadi antara lain karena sejak awal kemerdekaan Pemerintah Republik Indonesia (Pemerintah Pusat) tidak pernah memprioritaskan Semarang menjadi pusat kebudayaan walaupun memiliki kedudukan 
sebagai ibu kota provinsi atau pusat pemerintahan Jawa Tengah. Hal ini berbeda dari Bandung sebagai ibu kota Provinsi Jawa Barat yang sekaligus dijadikan sebagai pusat pengembangan budaya Sunda yang ditunjukkan dengan pendirian Sekolah Menengah Karawitan Indonesia (SMKI) dan Akademi Seni Tari (ASTI) di Bandung. Prioritas pengembangan kebudayaan Jawa diberikan kepada Surakarta dan Yogyakarta yang secara kultural dianggap memiliki kekayaan warisan budaya adiluhung, karena di dua kota itu masing-masing terdapat dua keraton yang merupakan pusat kebudayaan Jawa, yaitu Kasunanan dan Mangkunagaran (Surakarta) dan Kasultanan dan Pakualaman (Yogyakarta). Oleh karena itu, ketika Pemerintah Republik Indonesia merealisasikan pembangunan dalam bidang kebudayaan yang antara lain dilakukan dengan pendirian sekolahsekolah seni, untuk wilayah kebudayaan Jawa pilihan dijatuhkan pada Surakarta dan Yogyakarta, dengan pendirian Konservatori Karawitan Surakarta (Kokar 1950, kemudian menjadi SMKI, dan sekarang SMKN 8) dan Konservatori Tari (Konri 1961, kemudian menjadi SMKI Yogyakarta, dan sekarang SMKN 1). Kemudian, ketika Pemerintah Republik Indonesia akan mengembangkan sekolah menengah seni di beberapa kota di Jawa pada dasawarsa 1970an, di Jawa Tengah pilihan dijatuhkan pada Banyumas dengan mendirikan SMKI (1978) yang dimaksudkan untuk mengembangkan kesenian Banyumas. Ketika Pemerintah Republik Indonesia mengembangkan pendidikan formal seni pada level akademi, untuk wilayah kebudayaan Jawa pilihan juga dijatuhkan pada Yogyakarta dan Surakarta dengan pendirian Akademi Seni Rupa Indonesia (ASRI, 1950), Akademi Seni Tari Indonesia (ASTI, 1963), dan Akademi Seni Karawitan Indonesia (ASKI, 1964). Sementara itu, ketika Pemerintah Orde Baru ingin mengembangkan kebudayaan melalui proyek Pembangunan Lima Tahun (Pelita) yang direalisasikan dengan pendirian pusat-pusat kesenian di beberapa ibu kota provinsi, untuk provinsi Jawa Tengah pilihan dijatuhkan pada Surakarta dengan mendirikan Pusat Kesenian Jawa Tengah (PKJT, 1970) (menjadi Taman
Budaya Jawa Tengah, 1980) yang memiliki tugas membina kesenian-kesenian yang tumbuh dan berkembang di daerah Jawa Tengah (Puguh, 2015: Bab III). Celakanya, budaya Semarangan luput atau tidak menjadi prioritas dalam program-program pembinaan seni yang dilakukan oleh PKJT.

Fakta-fakta itu memberikan bukti, bahwa Semarang tidak pernah menjadi prioritas dalam pengembangan bidang kebudayaan. Pemerintah Republik Indonesia menganggap, bahwa Semarang tidak memiliki basis kultural yang kuat untuk pendirian sekolah seni atau pusat kesenian. Dengan demikian, dapat dipahami bahwa budaya Jawa Surakarta dan Yogyakarta tampil lebih dominan daripada budaya Semarangan dalam panggung budaya nasional, karena sejak awal kemerdekaan telah menjadi salah satu fokus perhatian Pemerintah Republik Indonesia untuk dikembangkan. Budaya Banyumas juga tampak lebih mampu tampil dan menjadi identitas budaya warga se-eks Keresidenan Banyumas. Kesenian gagrag banyumasan relatif lebih dikenal masyarakat luas daripada kesenian gagrag Semarangan. Dengan kata lain, pada masa kemerdekaan Pemerintah Daerah (Kotapraja, Kotamadya, dan Kota) Semarang dan masyarakat Semarang harus "berjuang sendiri" untuk mengembangkan kebudayaannnya tanpa campur tangan dari Pemerintah Republik Indonesia dalam bentuk pendirian sekolah/ akademi seni atau pusat kesenian. Itulah salah satu sebab mengapa sampai saat ini budaya Semarangan belum dapat tampil dalam panggung budaya nasional.

\section{SIMPULAN}

Berdasar uraian di atas dapat disampaikan bahwa Kota Semarang memiliki warisan budaya Semarangan yang berupa seni (rupa dan pertunjukan) dan upacara tradisi. Keberadaan seni dan upacara tradisi itu mengalami pasang surut. Pemerintah dan masyarakat Semarang telah melakukan upaya-upaya untuk melestarikan dan mengembangkan khazanah budaya yang dimilikinya. Dalam perjalanan sejarah itu, tampak bahwa budaya Semarangan belum mampu mencapai puncak 
perkembangannya, sehingga dapat tampil dalam panggung kehidupan budaya nasional. Keberadaan sebagian budaya Semarangan yaitu karawitan dan macapat Semarangan, serta upacara tradisi pengantin Semarang termarjinalisasi oleh kebudayaan Jawa yang lebih dominan berkembang di Kota Semarang yaitu kebudayaan Jawa Surakarta. Apabila terdapat keinginan untuk menampilkan budaya Semarang dalam konstelasi budaya nasional tentu Pemerintah Kota dan masyarakat Semarang perlu melakukan suatu politik kebudayaan yang berupa langkah-langkah strategis untuk melestarikan dan mengembangkan kebudayaan Semarangan. Hal ini dilakukan dengan membuat kebijakan budaya dan mengimplementasikannya secara konsisten dan berkelanjutan. Tanpa adanya suatu politik kebudayaan yang menempatkan aspek budaya pada posisi yang setara dengan aspek-aspek kehidupan lainnya dalam proses pembangunan, mustahil Semarang akan tampil dalam panggung budaya nasional.

\section{REFERENSI}

Bogaerts, Els (2011). “'Kemana Arah Kebudajaan Kita', Menggagas Kembali Kebudayaan di Indonesia pada Masa Dekolonisasi”, dalam Jennifer Lindsay dan Maya H.T. Liem, ed. Ahli Waris Budaya Dunia: Menjadi Indonesia, 1950-1965. Denpasar-Jakarta: Pustaka Larasan dan KITLV.

Hellman, Joergen (1999). "Longser Antar Pulau: Indonesian Cultural Politics and the Revitalisation of Traditional Theatre". Department of Social Anthropology University Goteborg, Sweden.

Jones, Tod (2005). "Indonesian Cultural Policy, 1950-2003: Culture, Institutions, Government". Thesis is presented for the Degree of Doctorate of Philosophy of Curtin University of Technology Perth.

Lindsay, Jennifer (1995). "Cultural Policy and the Performing Art in Southeast Asia", Bijdragen Toot de Taal-, Land-en Volkenkunde, Deel 151, 4e Aflevering.
Parani, Julianti (2011). Seni Pertunjukan Indonesia: Suatu Politik Budaya. Jakarta: Penerbit Nalar-Kajian Seni Pertunjukan Institut Kesenian-Kelola.

Puguh, Dhanang Respati, dkk. (2009). "Laporan Akhir Naskah Akademik tentang Pelestarian, Pengembangan, dan Pemanfaatan Seni dan Upacara Tradisi di Kota Semarang”. Dinas Kebudayaan dan Pariwisata Kota Semarang.

Puguh, Dhanang Respati dkk. (1998/1999). "Penataan Kesenian Gambang Semarang sebagai Identitas Budaya Semarang". Laporan Akhir Penelitian Hibah Bersaing Perguruan Tinggi Direktorat Denderal Pendidikan Tinggi Departemen Pendidikan dan Kebudayaan, Tahun I.

(1999/2000). "Penataan

Kesenian Gambang Semarang sebagai Identitas Budaya Semarang”. Laporan Akhir Penelitian Hibah Bersaing Perguruan Tinggi Direktorat Denderal Pendidikan Tinggi Departemen Pendidikan dan Kebudayaan, Tahun II.

Puguh, Dhanang Respati, dkk. (2003). "Sosialisasi dan Pelatihan Hasil Penataan Kesenian Gambang Semarang sebagai Identitas Budaya untuk Menunjang Pariwisata di Kota Semarang”. Laporan Kegiatan Pengabdian kepada Masyarakat Program IPTEKS Direktorat Pembinaan dan Pengabdian kepada Masyarakat Direktorat Jenderal Pendidikan Tinggi Departemen Pendidikan dan Kebudayaan.

Puguh, Dhanang Respati (1995). "Seni Pertunjukan Gambang Semarang: Sebuah Rekonstruksi oleh Tim Fakultas Sastra Universitas Diponegoro". Makalah Lokakarya Kesenian Gambang Semarang yang diselenggarakan atas kerja sama antara Fakultas Sastra Undip - Dewan Kesenian Jawa Tengah - Akademi Pariwisata, 14 November 1995.

(2013). "Generasi Muda dan Gambang Semarang”. Makalah Sarasehan Seni Kota Semarang yang diselenggarakan oleh Dinas Kebudayaan dan Pariwisata Kota Semarang di 
Balaikota Semarang pada 6 November 2013.

(2015). “Mengagungkan

Kembali Seni Pertunjukan Tradisi

Keraton: Politik Kebudayaan Jawa

Surakarta 1950an-1990an”. Disertasi pada

Program Pascasarjana Fakultas Ilmu

Budaya Universitas Gadjah Mada.

Rochwulaningsih, Yety, Dhanang Respati

Puguh, Mahendra Pudji Utama (2010).

"Penulisan dan Pengkajian Upacara

Tradisional di Kota Semarang”. Seksi Nilai

Budaya Bidang Nilai Budaya Seni dan

Film Dinas Kebudayaan dan Pariwisata

Provinsi Jawa Tengah.

Selayang Pandang Kota Semarang (Glance of Semarang City) (2008). Semarang: Kantor Informasi dan Komunikasi Kota Semarang.

Tata Cara Upacara Pengantin Gaya Semarangan. (2009). Semarang: Dinas Kebudayaan dan Pariwisata Kota Semarang.

Utama, Mahendra Pudji dan Dhanang Respati Puguh (2013). "Bertahan di Tengah Badai: Seni Pertunjukan Tradisi Semarangan", dalam Dhanang Respati Puguh, dkk., Membedah Sejarah dan Budaya Maritim, Merajut Keindonesiaan. Semarang: Program Magister Ilmu Sejarah Fakultas Ilmu Budaya Program Pascasarjana Universitas Diponegoro, Masyarakat Sejarawan Indonesia Jawa Tengah, UPT Undip Press.

Yuliati, Dewi (2009). Mengungkap Sejarah dan Pesona Motif Batik Semarang. Semarang: Badan Penerbit Universitas Diponegoro. 